\title{
Natural products utilization
}

\author{
Milen I. Georgiev
}

Received: 9 May 2014/ Accepted: 12 May 2014/Published online: 17 May 2014

(C) Springer Science+Business Media Dordrecht 2014

In November 2013 in Bansko, Bulgaria, over 230 scientists and exhibitors attended the meeting Natural Products Utilization: from Plants to Pharmacy Shelf (ICNPU-2013; www.icnpu2013.cim.bg), jointly organized by the Stephan Angeloff Institute of Microbiology and Institute of Organic Chemistry with Centre of Phytochemistry. A number of non-profit organizations as the Phytochemical Society of Europe (PSE), the Association for Medicinal and Aromatic Plants of Southeast European Countries (AMAPSEEC) and the Southeast European Network on Phytochemistry and Chemistry of Natural Products for Green and Sustainable Growth (SEE PhytochChem NET) supported the meeting. The international organizing committee of ICNPU-2013 assembled an exciting and diverse program, featuring keynote session given by Prof. Dr. Bharat B. Aggarwal (The University of Texas M. D. Anderson Cancer Center, USA), followed consecutively by 17 plenary and invited lectures, 38 short oral presentations and 140 posters. World-renowned experts and attendees from 40 different countries discussed the latest developments on the field with special emphasis on the emerging methods for treatment and prevention of malignancies, sustainable production and use of natural products and the modern analytical platforms

M. I. Georgiev ( $\bowtie)$

Laboratory of Applied Biotechnologies, The Stephan Angeloff Institute of Microbiology, Bulgarian Academy of Sciences, 139 Ruski Blvd., 4000 Plovdiv, Bulgaria e-mail: milengeorgiev@gbg.bg (e.g. omics approaches). This editorial article aims at giving insight into natural products-related research covered by the ICNPU-2013 meeting.

The broad chemical diversity of plants has been exploited for centuries by humans to diminish and prevent pain, for clothing and shelter, for use in religious ceremony, to produce pleasure, and to cure various human ailments (De Luca et al. 2012; Georgiev 2013). Today, over a quarter of the modern medicines are derived either directly or indirectly from plants, especially in case of cancer therapy (60\%), infectious diseases $(75 \%)$, but also in the treatment of metabolic syndrome-related ailments and immunosuppression therapy. Surely, these numbers count on microbial sources as well, though the importance of plants in the production of pharmaceuticals is undoubtful. For instance, U.S. Food and Drug Administration (FDA) recently approved Fulyzaq (from the sap of Croton lechleri), the first anti-diarrheal drug for HIV/AIDS patients. Fulyzaq is, in fact, the second botanical drug approved by FDA after Veregen (extract from green tea leaves). In addition, World Health Organization (WHO) estimates, at least $80 \%$ of the population residing in developing countries still relies exclusively on traditional medicine for their primary health care needs (Georgiev 2013 and the literature cited therein). According to the Food and Agriculture Organization of UN (FAO 2009) world population is expected to grow by over a third until 2050, which suggests, in near future, mankind will face multiple challenges as: (1) more food (and fibre) 
have to be produced to feed the growing population; (2) more feed stocks for a potentially huge bioenergy market and iii) more medicines (inter alia of natural origin) to cure human diseases and disorders.

The growing importance of medicinal plants is illustrated by a set of comprehensive reviews on Astragalus (Fabaceae), Verbascum (Scrophulariaceae), Lamium and Agastache (Lamiaceae), their bioactive principles and record accomplishment in traditional use (Alipieva et al. 2014; Ionkova et al. 2014; Yordanova et al. 2014; Zielińska and Matkowski 2014). Nasopoulou et al. (2014) focuses on the opportunity to utilize the by-products of olive oil production (e.g. olive pomace and olive pomace oil) in production of sustainable functional food and nutraceuticals. The anti-inflammatory activities of virgin olive oil and olive pomace are also thoroughly discussed.

Curcumin, the yellow pigment of Curcuma longa L., has been employed in traditional Indian medicine, while within the EU it bears a status of food ingredient (E100) and is present in many food additives. Curcumin was reported a strong $\mathrm{NF}-\kappa \mathrm{B}$ inhibitor and apoptosis inducer with antioxidant, cholesterol-lowering, anti-inflammatory, and antimicrobial potential. Ilieva et al. (2014) covers the wide spectrum of pleiotropic activities of curcumin, including antitumor effects and protection of the normal bone marrow, besides its antineoplastic property in various malignant cell lines, such as cutaneous $\mathrm{T}$ cell lymphoma, acute myeloid leukemia and urinary bladder cancer cells.

Glycogen phosphorylase (GP; EC 2.4.1.1) is an important therapeutic target for the potential treatment of type 2 diabetes. The search of potent, selective and drug-like GP inhibitors uncovered a number of natural products with promising pharmaceutical and nutraceutical potential. An excellent review of Hayes et al. (2014) highlights the potential of natural products (and derivatives thereof) for regulation of blood glucose levels through glycogenolysis control by GP inhibition. Lojek et al. (2014) discusses the contemporary knowledge on the effects of natural compounds of botanical origin (especially polysaccharides and polyphenols, but also terpenes) on the metabolic activity of mammalian neutrophils (effector cells of the innate immune response). Charoonratana et al. (2014) summarizes an attempt on the utilization of high-performance liquid chromatography-mass spectrometry
(LC-MS) to investigate the chemical fingerprint, chemical constituents, and putative active ingredients of a traditional Thai antihypertensive herbal recipe (TTAH). Moreover, metabolic profiling of 10 possible TTAH constituents was performed and all were shown to have pharmaceutical properties. Attempts to prepare a suitable formulation of the TTAH, to standardize the amount of active ingredients per dose, and to improve patient compliance are also discussed. Further, Todorov et al. (2014) summarizes comprehensively the studies on the antiviral activity of Bulgarian medicinal plants. The effect of different extracts derived from in vitro propagated plants, the phytochemical composition and its influence on specific steps of the viral life cycle have been discussed as well.

In another interesting review, Chinou et al. (2014) highlights the regulation attempt of EU on herbal medicinal products. The new European legislation on herbal medicinal products, aiming to harmonize their use in the 28 member states, according to Directive 2004/24/EC (which actually amended the basic legislation of the previous Directive 2001/83/EC), is discussed. The Committee on Herbal Medicinal Products, established a decade ago at the European Medicines Agency, aims to provide community monographs and list entries on herbal substances and preparations. Since its establishment, 120 monographs have been prepared, offering scientific and regulatory standards for herbal medicinal products safety and efficacy. The herbal medicinal products can accordingly be placed on the market after quality, efficacy, and safety issues have been assessed following to the provisions of the legislation (Directives 2004/24/EC and 2001/83/EC). Adequate labeling information to patients and health care professionals is required in order to distinguish them from other product categories containing herbs-like products, as foods and food supplements, medical devices and cosmetics (Chinou et al. 2014).

Natural products extracts are commonly highly complex mixtures of active compounds and consequently their purification is in particular challenging and important task toward developing economically feasible processes. Counter-current chromatography (CCC) is a separation technique utilizing two immiscible phases, one as the stationary phase (retained in a spinning coil by centrifugal forces) and the second as a mobile phase. Skalicka-Woźniak and Garrard (2014) 
thoroughly discusses the advantages of CCC compared to the traditional liquid-solid separation methods, such as no irreversible adsorption, total recovery of the injected sample, minimal tailing of peaks, low risk of sample denaturation, the ability to accept particulates, and a low solvent consumption. In order to assist users of CCC, authors generated a comprehensive phase selection table by distilling the solvent system information presented from CCC terpenoids purifications over the past 30 years.

Finally yet importantly, I am thankful to Editor-inChief Prof. Dr. Robert Verpoorte (Institute of Biology Leiden, The Netherlands) for inviting me to prepare this issue compilation as guest editor and for his continuous efforts in promoting natural products.

\section{References}

Alipieva KI, Orhan IE, Cankaya IIT, Kostadinova EP, Georgiev MI (2014) Treasure from garden: chemical profiling, pharmacology and biotechnology of mulleins. Phytochem Rev. doi:10.1007/s11101-014-9361-5

Charoonratana T, Songsak T, Monton C, Saingam W, Bunluepuech K, Suksaeree J, Sakunpak A, Kraisintu K (2014) Quantitative analysis and formulation development of a traditional Thai antihypertensive herbal recipe. Phytochem Rev. doi:10.1007/s11101-014-9359-z

Chinou I, Knoess W, Calapai G (2014) Regulation of herbal medicinal products in the EU: an up-to-date scientific review. Phytochem Rev. doi:10.1007/s11101-014-9354-4

De Luca V, Salim V, Atsumi SM, Yu F (2012) Mining the biodiversity of plants: a revolution in the making. Science 336:1658-1661

Food and Agriculture Organization of UN (2009) Global agriculture towards 2050. www.fao.org/fileadmin/templates/ wsfs/docs/Issues_papers/HLEF2050_Global_Agriculture. pdf. Retrieved May 2014
Georgiev MI (2013) Coming back to nature: plants as a vital source of pharmaceutically important metabolites - Part II A. Curr Med Chem 20:851

Hayes JM, Kantsadi AL, Leonidas DD (2014) Natural products and their derivatives as inhibitors of glycogen phosphorylase: potential treatment for type 2 diabetes. Phytochem Rev. doi:10.1007/s11101-014-9360-6

Ilieva Y, Kaloyanov K, Yosifov D, Robev B, Zhelezova I, Genova M, Mihova A, Balatzenko G, Zaharieva MM, Berger MR, Konstantinov SM (2014) Antineoplastic potential of curcumin (cooperative study in Bulgaria and Germany). Phytochem Rev. doi:10.1007/s11101-014-9351-7

Ionkova I, Shkondrov A, Krasteva I, Ionkov T (2014) Recent progress in phytochemistry, pharmacology and biotechnology of Astragalus saponins. Phytochem Rev. doi:10. 1007/s11101-014-9347-3

Lojek A, Denev P, Ciz M, Vasicek O, Kratchanova M (2014) The effects of biologically active substances in medicinal plants on the metabolic activity of neutrophils. Phytochem Rev. doi:10.1007/s11101-014-9340-x

Nasopoulou C, Karantonis HC, Detopoulou M, Demopoulos CA, Zabetakis I (2014) Exploiting the anti-inflammatory properties of olive (Olea europaea) in the sustainable production of functional food and neutraceuticals. Phytochem Rev. doi:10.1007/s11101-014-9350-8

Skalicka-Woźniak K, Garrard I (2014) Counter-current chromatography for the separation of terpenoids: a comprehensive review with respect to the solvent systems employed. Phytochem Rev. doi:10.1007/s11101-0149348-2

Todorov D, Hinkov A, Shishkova K, Shishkov S (2014) Antiviral potential of Bulgarian medicinal plants. Phytochem Rev. doi:10.1007/s11101-014-9357-1

Yordanova ZP, Zhiponova MK, Iakimova ET, Dimitrova MA, Kapchina-Toteva VM (2014) Revealing the reviving secret of the white dead nettle (Lamium album L.). Phytochem Rev. doi:10.1007/s11101-014-9356-2

Zielińska S, Matkowski A (2014) Phytochemistry and bioactivity of aromatic and medicinal plants from the genus $A$ gastache (Lamiaceae). Phytochem Rev. doi:10.1007/ s11101-014-9349-1 